\title{
Titanium Elastic Nail - Complications in the Treatment of Paediatric Diaphyseal Fracture of Femur
}

\author{
Saikat Sarkar, Ranadeb Bandyopadhyay and Arindam Mukherjee*
}

Department of Orthopaedics, B.S. Medical College, India

\begin{abstract}
Background: Femoral shaft fracture is the most common major paediatric orthopaedic. For generations traction and casting was the standard treatment for all femoral shaft fractures in children. Over the past two decades the advantages of fixation and rapid mobilisation have been increasingly recognised.

Methods: A prospective study was conducted in five private hospitals in the district of Bankura, West Bengal over a period of two years (April 2010 to March 2012) on 70 patients with closed shaft femur fractures between 6- 14 years age of either sex. The aim was to find out the short term complications of titanium elastic nailing in diaphyseal fracture of femur in children and compare the findings of this study with pre- existing studies in this field.

Results: In our study the most common complication was pain at nail entry site $(60 \%) .5 .71 \%$ had local inflammatory reaction due to nails. Superficial infection occurred in $2.85 \%$. At the end of 1 year, $2.85 \%$ had limb length discripancies. Proximal migration occurred in $2.85 \%$. $2.85 \%$ encountered acute reactive synovitis, $5.71 \%$ developed angulation of fracture site and $2.85 \%$ developed per operative breakage of nail.

Conclusion: The treatment of paediatric shaft femur fracture has been drastically changed over the last two decades to internal fixation by elastically stable intra- medullary nail (ESIN). In our study, we encountered only a few complications most of them being minor. Most of the complications were surgical technique related and were seen at the initial phase of the learning curve.
\end{abstract}

Keywords: Femoral shaft fracture, hip spica, elastically stable intra-medullary nail, titanium elastic nails, limb length discrepancies.

\section{INTRODUCTION}

Femoral shaft fracture is the most common major paediatric orthopaedic injury that most orthopaedist will treat routinely and is the most common paediatric orthopaedic injury requiring hospitalisation. When subtrochanteric and supracondylar fractures are included the femoral shaft fractures represents about $1.6 \%$ of all bony injuries in children.

Management of femoral diaphyseal fractures in the age group of 6-14 years is highly controversial. Femoral shaft fractures in the paediatric patients have traditionally been treated non- operatively with either early spica cast or a period of traction followed by application of hip spica cast until the time of fracture union. This is the accepted standard of care for young children (usually age $<6$ years), but complications such as mal- union, joint stiffness, angulation, shortening and delay in functional recovery are not uncommon in older children if managed in this manner. Moreover, conservative treatment results in prolonged hospitalisation causing more burden on the hospital and financial losses to the family and parents [1].

*Address correspondence to this author at the B.S. Medical College, P.O. Kenduadihi, Gobindanagar, Bankura- 722102, WB, India;

Tel: +918900338029/+918436118646; E-mail: arindamm02@gmail.com

${ }^{\S}$ Place of study: Bankura, West Bengal. India.
During the past few decades, some forms of internal fixation in the form of plate fixation, rigid intra- medullary nailing, enders nailing, titanium nailing have been advocated but the controversy regarding the ideal implant to treat paediatric femoral fractures still exists [1]. The ideal device to treat most femoral fractures in children would be a simple, load sharing internal splint that allows mobilisation and maintenance of alignment and extremity length until bridging callus forms. Titanium elastic nails offered these features. Though titanium elastic nails fixation is a good treatment option it is not free of complications [2,3].

This endeavour is an honest effort to analyse the short term complications of titanium elastic nailing in paediatric diaphyseal femoral fractures in a new set up where conservative treatment was performed in greater magnitude and to look in to factors causing them and possibly to provide a way as to how to minimise these complications.

Mazda et al. pointed out a technique related complication that occurred in 10 of their 34 patients. Rods were left too long and caused painful bursae and limited knee flexion. All 10 patients had the nail removed 2- 5 months after surgery [4]. Flynn et al. compared traction and spica casting with titanium elastic nails for treatment of femoral fractures in 83 school aged children. The overall complication rate was $34 \%$ in the traction group and $21 \%$ in the elastic nail group [5]. Narayanan et al. looked at one centre's learning curve with titanium elastic nail, studying the complications of 79 patients over a 5 year period. There were 41 entry point 
irritations, 8 malunions and 2 re-fractures [6]. Luhmann et al. reported 21 complications in 43 patients with TENS. Most complications were minor but hypertrophic non- union and a septic joint occurred in their cohort [7].

\section{MATERIALS AND METHODS}

A prospective study was conducted in five private hospitals in the district of Bankura, West Bengal over a period of two years (April 2010 - March 2012) on the patients with closed shaft femur fractures in the age group of 6 years -14 years of either sex. The inclusion criteria also included those without any other fracture to either lower limb and whose fixation was done within 7 days post injury. Children with open fractures, outside this age group with concomitant head injury, bilateral femur fracture or associated fracture of either limb whose fixation was done after 7 days were excluded from the study. No control group was used.

The aims and objectives of the study were:

1. To find out the short term complications of titanium elastic nailing in diaphyseal fracture of femur in children.

2. Compare the findings of this study with pre- existing studies in this field.

After obtaining ethical clearance approved by the Ethical Committee of the District of Bankura an informed consent was taken from the patients in their own language.

Pre- operative evaluation included radiograph of the fractured femur taken full length both the antero- posterior (A-P) and lateral views. Parameters studied were (1) clinical features of union, (2) radiological features of union, (3) range of motion [ROM] of the affected side knee, (4) limb lengthening / shortening, (5) angulation / loss of alignment, (6) all other major / minor complications found during the study.

Patients were operated under general or spinal anaesthesia in supine position on fracture table. Traction was applied and reduction checked under image intensifier. The leg was prepared and draped with the thigh exposed (hip to knee). The image intensifier was used to localise the placement of skin incisions by viewing the distal femur in AP and lateral views. A $4.5 \mathrm{~mm}$ drill bit or awl was used to make the hole in the cortex of the bone. Selected pair (nail diameter $40 \%$ of femoral medullary canal diameter) of prebent (usually 3 times the diameter of the medullary canal) taken, first nail introduced from the lateral side just upto the fracture. From the medial side another tens nail was inserted just before the fracture. Now under image intensifier one nail was introduced after achieving fracture reduction and then another nail was introduced. The two nails are driven into the proximal end of the femur with one driven towards the femoral neck and the other towards the greater trochanter. The protruding parts of the nails were cut keeping a small part outside the distal femoral entry point. No external immobiliser was used in any of the cases.

The results obtained were analysed and compared with similar results obtained from various literature.

\section{RESULTS}

The results of the 70 patients who were treated in the five private hospitals in Bankura were studied systematically during the period from April 2010 to March 2012 with a follow up period from 4 months to 15 months. In our series the range of age of patients was from 6 years to 14 years with an average of 8 years. Out of 70 patients, $52(74.28 \%)$ were boys and $18(25.72 \%)$ were girls. Male: female ratio was 2.89: 1 and 49 children (70\%) had injury on the right side. In 42 patients $(60 \%)$ the mechanism of injury was due to motor vehicle accident, $22(31.42 \%)$ were due to fall from height while remaining 4 (8.58\%) were due to sports injury.

$44(62.86 \%)$ children had fracture in the mid- shaft (Fig. 1), $15(21.42 \%)$ in the upper third while $11(15.72 \%)$ in the lower third. $42(60 \%)$ were transverse, $16(22.8 \%)$ oblique, 7 $(10 \%)$ spiral and $5(7.2 \%)$ were comminuted fractures. 45 $(64.28 \%)$ children had weight between $20 \mathrm{kgs}-29 \mathrm{kgs}, 15$ (21.42\%) between $15 \mathrm{kgs}-19 \mathrm{kgs}, 7$ (10\%) between 40- 49kgs while only $3(4.3 \%)$ were between $30-39 \mathrm{kgs}$. Mean interval between injury and TENS nail fixation was 4 days ( 2 days to 6 days). Mean post- operative hospital stay was 4.13 days (min: 2 days to max: 11 days). Minimum nail size used was $2.5 \mathrm{~mm}$ while maximum nail size used was $4 \mathrm{~mm}$. All the 70 cases were managed by closed reduction (Fig. 2). Callus appeared within 3 weeks, circumferential callus was seen within 5-6 weeks and full radiological union was achieved by 8 weeks to 10 weeks (mean 8.3 weeks). Time of nail removal varied from 6 months to 14 months with a mean of 8 months.

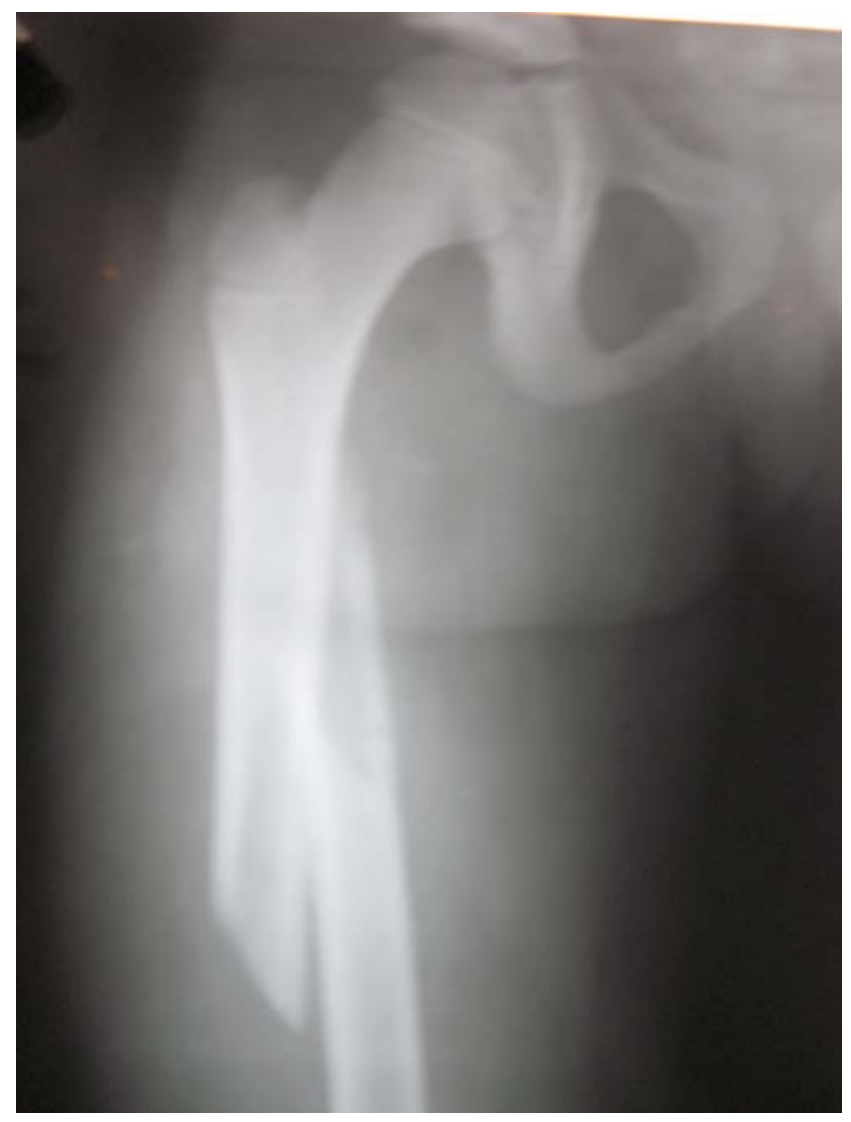

Fig. (1). Fracture mid- shaft right femur. 


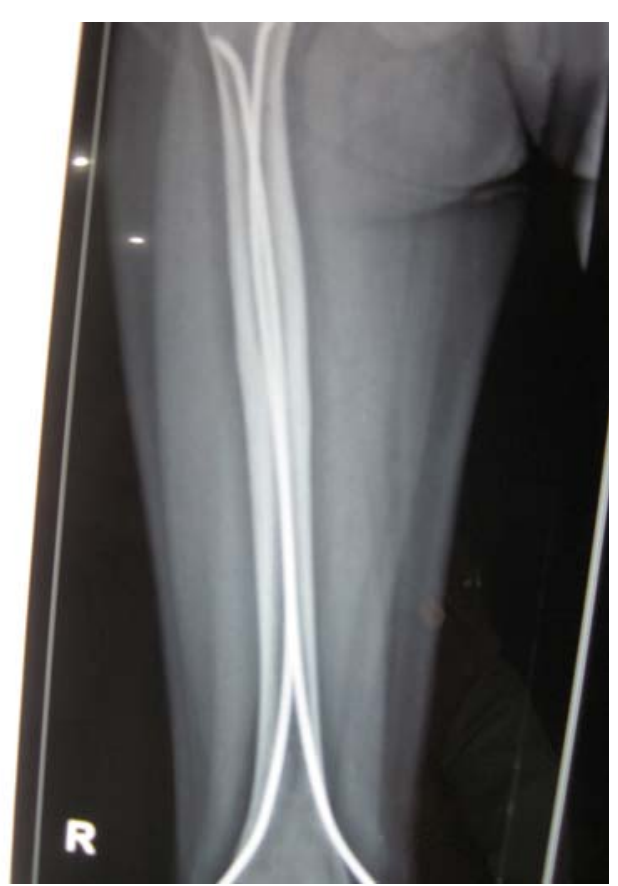

Fig. (2). immediate post- operative radiograph showing good alignment after fixation with TENS.

In our study we detected several short term complications. In our study we found the most common complication was pain at nail entry site (14 of $70,60 \%$ ) which was relieved when nail was removed. 4 cases $(5.71 \%)$ had local inflammatory reaction due to nails, in the form of ulceration (Figs. 3, 4) or bursa formation (Figs. 5, 6). Superficial infection occurred in 2 cases $(2.85 \%)$. At the end of 1 year, 2 cases $(2.85 \%)$ of limb length discripancies in which the injured limb was about $1.5 \mathrm{cms}$ greater than the normal limb. Proximal migration occurred in 2 cases $(2.85 \%)$. Acute reactive synovitis due to nails at 7 months post operatively occurred in 2 cases $(2.85 \%$ ) (Figs. 7, 8). There were 2 cases $(2.85 \%)$ of knee stiffness (Fig. 9). There were also 2 cases $(2.85 \%)$ of per operative breakage of nail and no part was outside the cortex (Fig. 10). Varus angulation of fracture site occurred in 4 cases $(5.71 \%$ ) (Fig. 11). We experienced no case of delayed or non- union or deep infection in our series (Table 1).

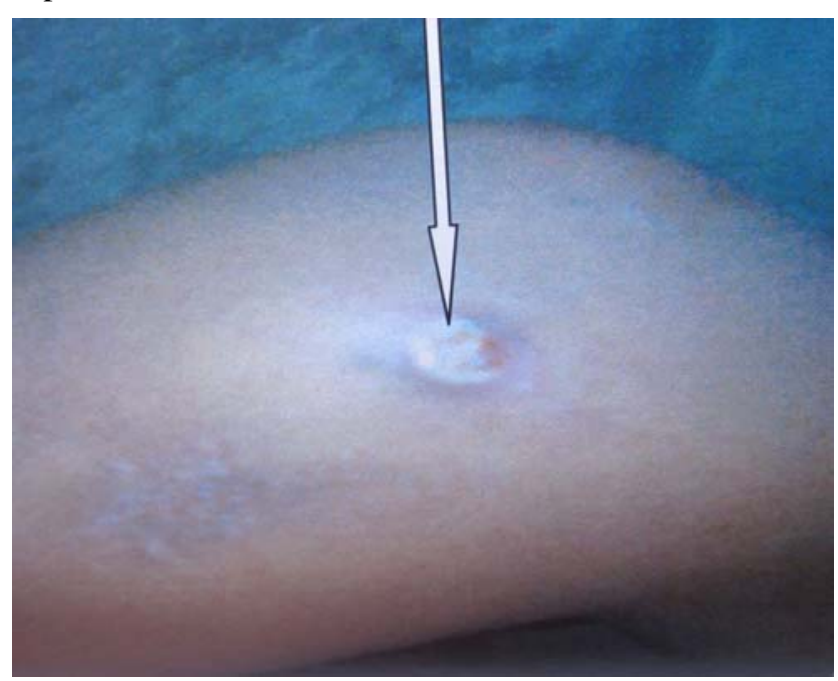

Fig. (3). inflammatory reaction due to TENS nail, medial entry.

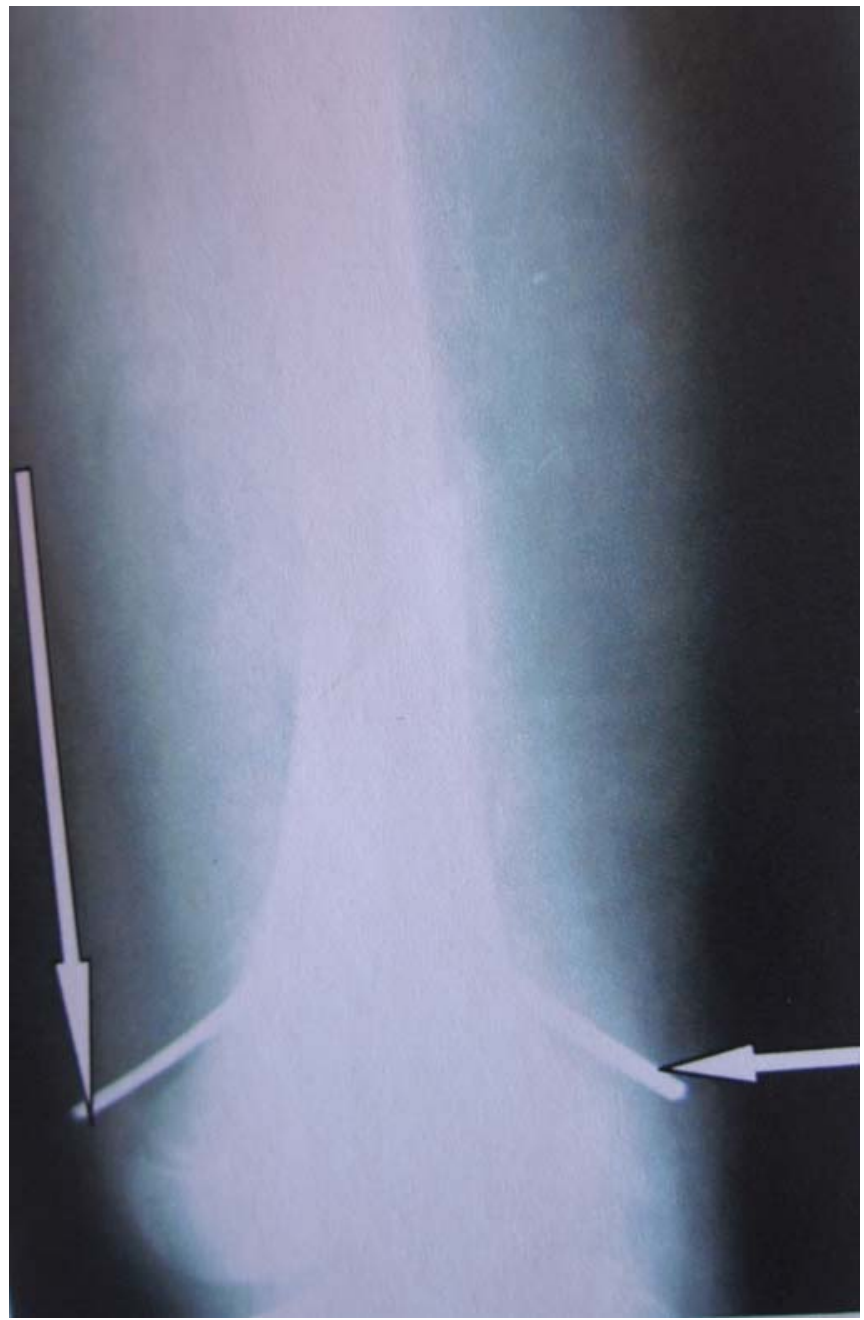

Fig. (4). post- operative radiograph of Fig. (3) showing excess nail length outside the cortices.

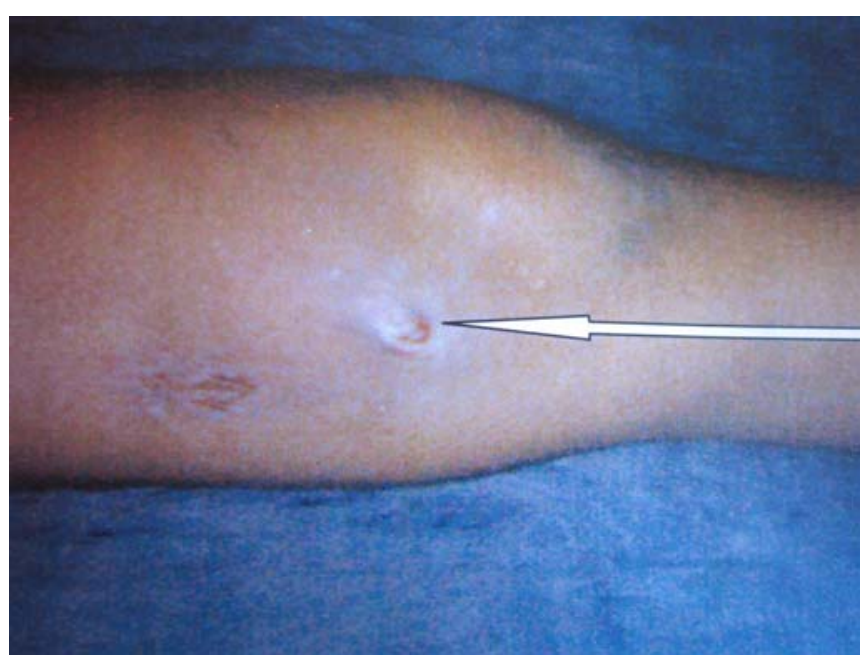

Fig. (5). bursa formation and subsequent ulceration at entry site.

\section{DISCUSSION}

The treatment of paediatric shaft femur fracture has been drastically changed over the last two decades. Internal fixation of paediatric shaft femur fracture by elastically stable intra- medullary nail (ESIN) is gradually replacing conservative treatment. A better understanding of the elastic 
nailing procedure, overall promising results published in different international journals and patient's demand probably has instilled confidence in our minds to begin this apparently new mode of fixation. However, starting titanium nailing in our set up was not a smooth sailing initially but we gradually did overcome the initial hindrance [8].

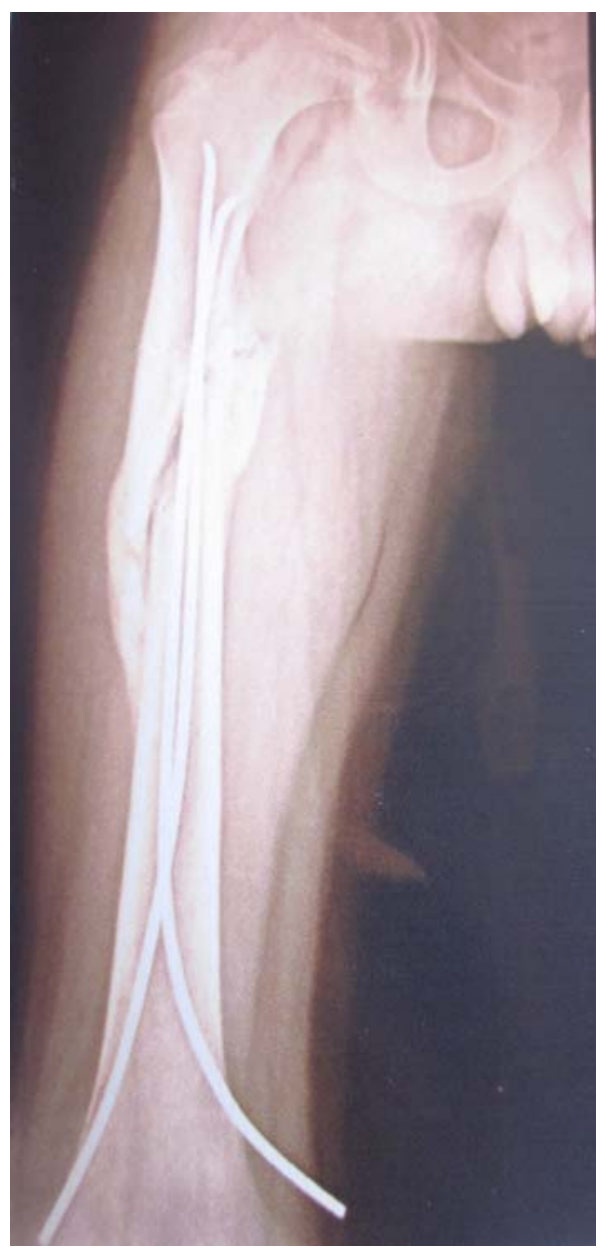

Fig. (6). post- operative radiograph of Fig. (5) showing prominent medial end.

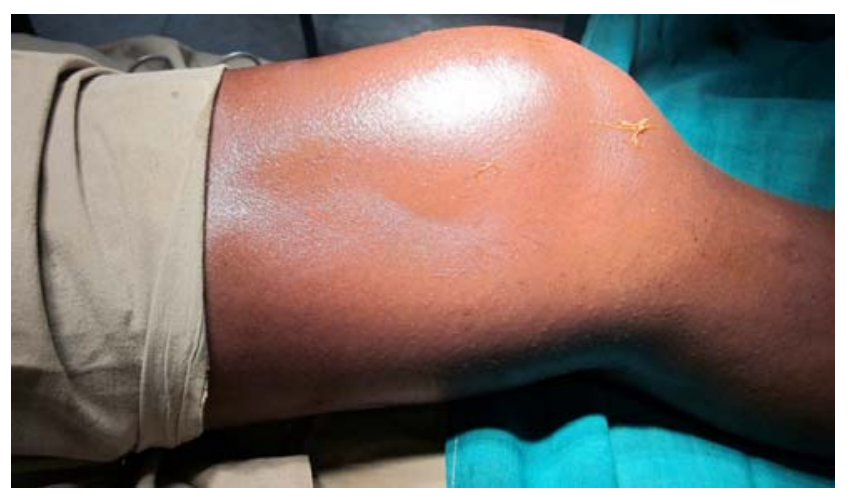

Fig. (7). Inflammatory reaction to nail (acute knee swelling).

Our study consisted of a cohort of 70 cases of shaft femur fractures in the age group 6- 14 years treated by titanium elastic nailing. All patients were operated as early as possible to achieve closed reduction and definitely to get the best result. In our cases the interval between the injury and operation ranged from 2 days to 6 days with a mean of

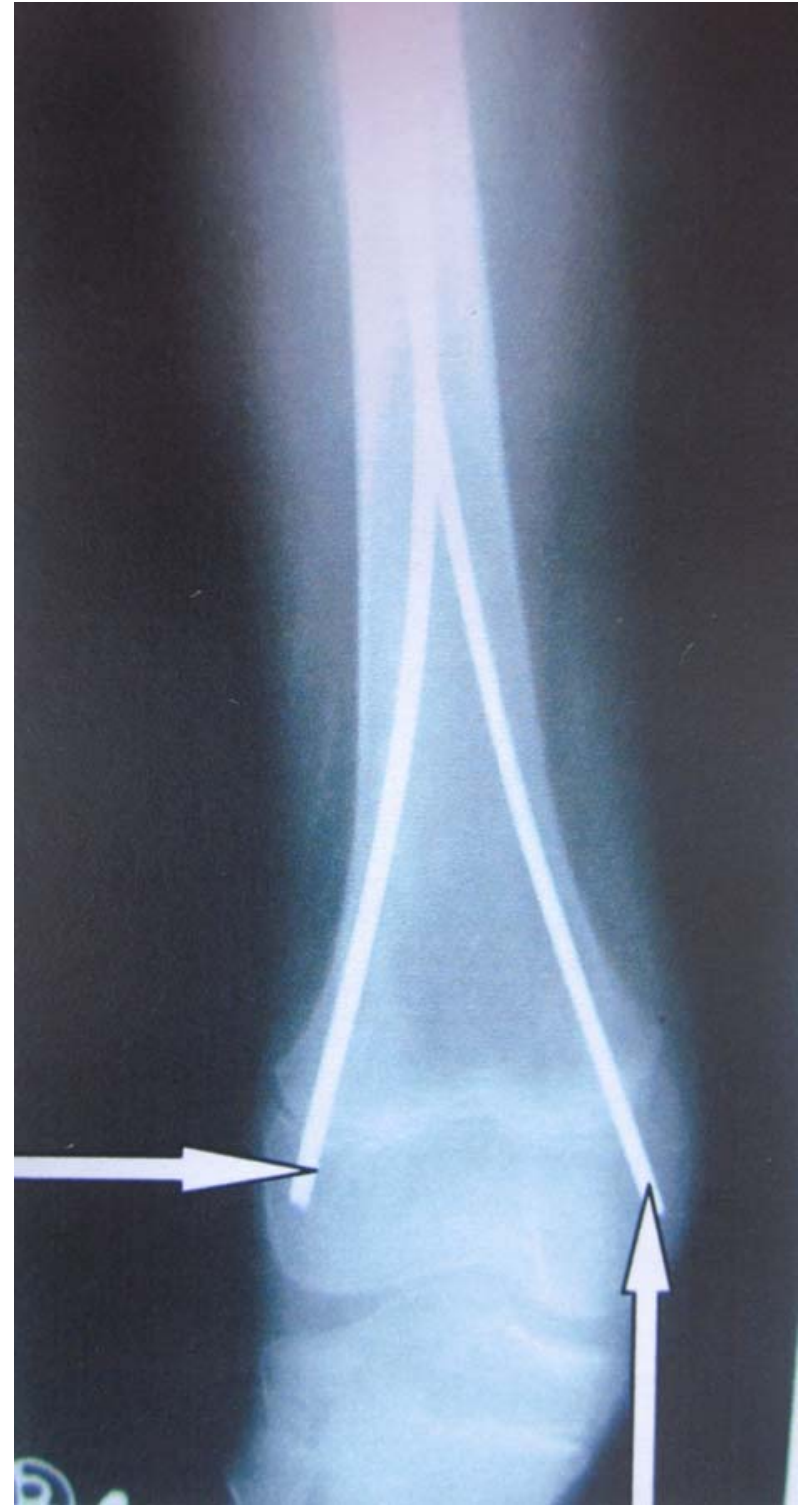

Fig. (8). Post- operative radiograph of Fig. (7).

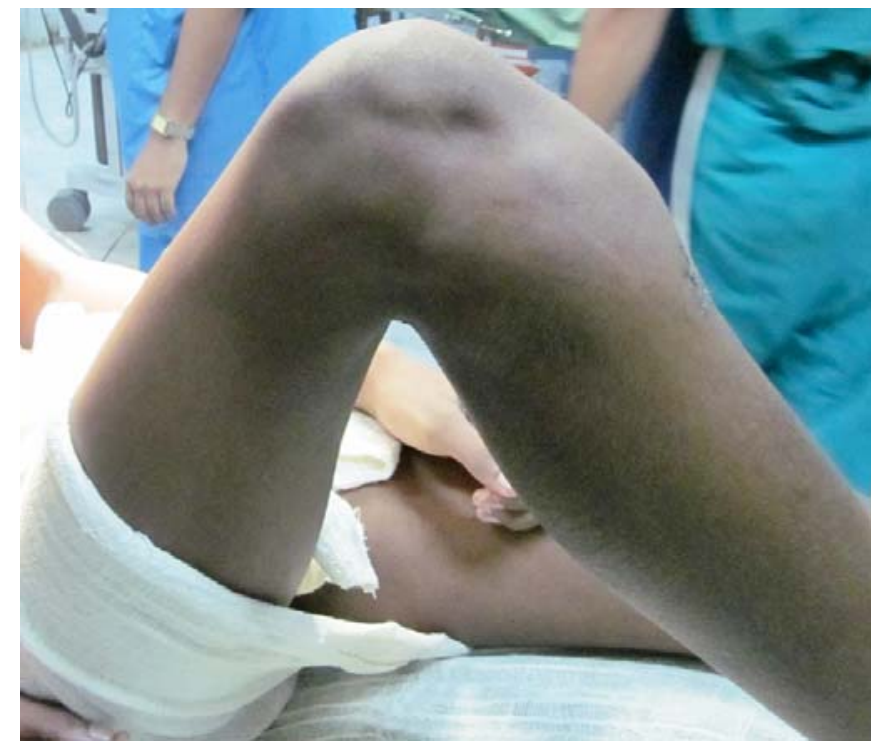

Fig. (9). Clinical photo showing knee stiffness. 


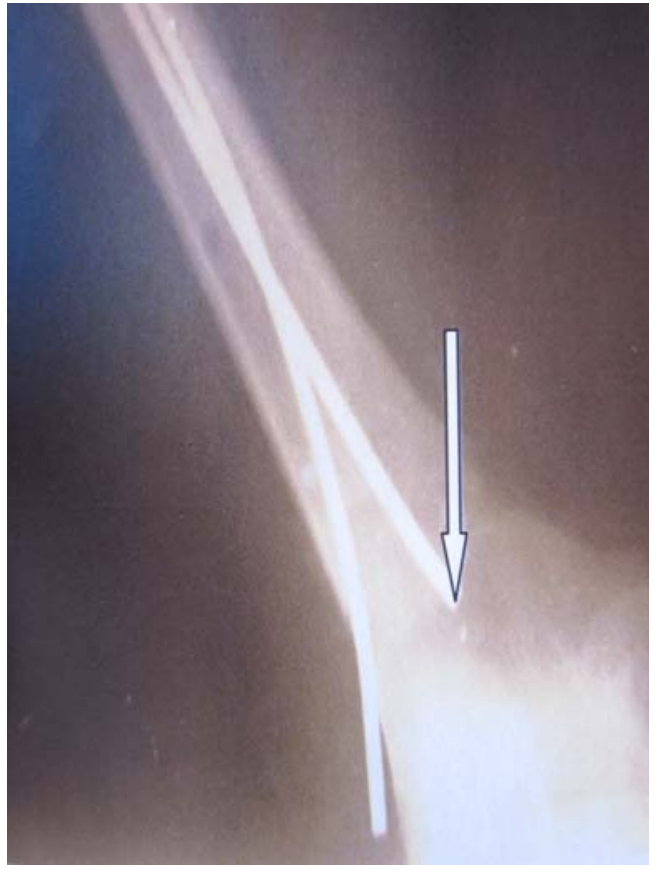

Fig. (10). post- operative radiograph showing intra- operative breakage of nail.

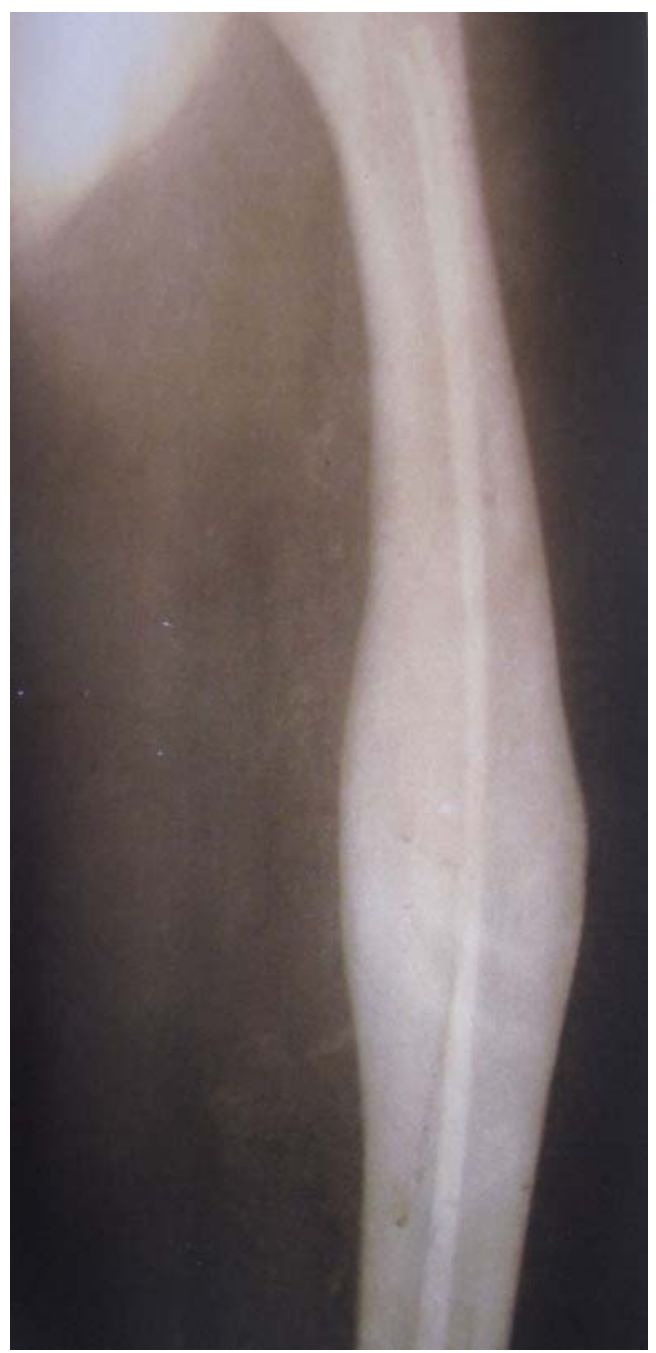

Fig. (11). post- operative radiograph at the end of 1 year showing varus angulation.
Table 1. Complications

\begin{tabular}{|l|c|c|}
\hline \multicolumn{1}{|c|}{ Complications } & Number & $\begin{array}{c}\text { Percentage } \\
\text { (Out of 70) }\end{array}$ \\
\hline \hline Pain at the site of nail insertion & 14 & $20 \%$ \\
\hline $\begin{array}{l}\text { Inflammatory reaction/bursitis } \\
\text { at the entry site }\end{array}$ & 4 & $5.71 \%$ \\
\hline Superficial infection & 2 & $2.85 \%$ \\
\hline Deep infection & 0 & 0 \\
\hline Knee swelling (synovitis due to nails) & 2 & $2.85 \%$ \\
\hline Knee stiffness & 2 & $2.85 \%$ \\
\hline Leg length discrepancy & 2 & $2.85 \%$ \\
\hline Proximal nail migration & 2 & $2.85 \%$ \\
\hline $\begin{array}{l}\text { Angulation exceeding the guidelinesat } \\
\text { the final follow up }\end{array}$ & 4 & $5.71 \%$ \\
\hline Delayed union & 0 & 0 \\
\hline Non union & 2 & 0 \\
\hline Pre- operative breakage of nail & & $2.85 \%$ \\
\hline
\end{tabular}

4 days, which is definitely late in comparison to western scenario. The average operation time ranged from 30 minutes to 1 hour 15 minutes. Operation time gradually decreased with experience. In no case external immobiliser or brace was used. All cases were followed up at 2 weeks, 4 weeks, 6 weeks, 8 weeks, 12 weeks and at 6months. Hardware was usually removed after 6 months. At each visit, post operative radiological evaluation included an assessment of the position of the nails, frontal and sagittal alignment, loss of reduction, callus formation, disturbance of trochanteric growth, osteonecrosis of femoral head and femoral length. Varus and valgus angulation was measured from the anatomical axis. Flexion and extension was measured directly. Circumferential callus formation, the visibility of the fracture line, leg length discrepancy and malalignment were recorded at each post- operative visit in order to monitor remodelling and detect delayed union or deformity.

Early weight bearing was allowed in case of transverse mid- shaft fracture with adequate fixation but for others weight bearing was started with signs of union seen radiologically. Many studies show that complications are more when body weight $>50 \mathrm{kgs}$. Ho et al. reported a $34 \%$ complication rate in patients older than 10 years but only $9 \%$ complication rate in those younger than 10 years. This emphasises the concept that complications are higher in older and heavier children [9]. Our study revealed no such findings as we dealt with children weighing $<50 \mathrm{kgs}$ though some of them were in the age group 10- 14 years. Regarding complications we found that most were minor and surgical technique related which reflects the view of Narayanan et al.

In our study we found the most common complication was pain at nail entry site (14 of $70,60 \%)$ which was relieved when nail was removed. 4 cases $(5.71 \%)$ had local inflammatory reaction due to nails, in the form of ulceration (Figs. 3, 4) or bursa formation (Figs. 5, 6). Superficial infection occurred in 2 cases $(2.85 \%)$. At the end of 1 year, 2 
cases $(2.85 \%)$ of limb length discripancies in which the injured limb was about $1.5 \mathrm{cms}$ greater than the normal limb. Proximal migration occurred in 2 cases (2.85\%). Acute reactive synovitis due to nails at 7 months post operatively occurred in 2 cases $(2.85 \%$ ) (Figs. 7, 8). There were 2 cases $(2.85 \%)$ of knee stiffness (Fig. 9). There were also 2 cases $(2.85 \%)$ of per operative breakage of nail and no part was outside the cortex (Fig. 10). Varus angulation of fracture site occurred in 4 cases $(5.71 \%)$ (Fig. 11) (Table 1).

Over the past two decades the advantage of fixation of paediatric femoral shaft fractures by elastically stable intramedullary nails have been increasingly accepted [10]. In our study of 70 paediatric femoral shaft fractures treated by titanium elastic nails, we encountered only a few complications (during a follow up of 6 to 15 months), most of them being minor. Most of the complications were surgical technique related and were seen at the initial phase of the learning curve. This reflects what Mazda et al. obtained in their study. The most important complication was pain at the nail entry site followed by inflammatory reaction due to the nails projecting the cortices at the entry. This can be minimised by keeping the ends of the cut nails flushed with the cortices avoiding a bend at the end. For stable transverse fracture mid- shaft femur, if titanium nailing is done properly we can allow very early weight bearing but for oblique or transverse fracture a delayed weight bearing is recommended. Varus angulation in the fracture site encountered in 4 cases were probably due to early weight bearing in oblique fractures following elastic nailing. However, all the 4 cases of angulation remodelled well on follow up. No further operative procedure was required. In the 2 cases of proximal migration, the nail was removed after bony union was evident on radiograph. The complications encountered in the study were got rid of with experience. Overall experience in our study shows that titanium elastic nailing for paediatric shaft femur fracture is a safe, cost effective procedure resulting in very few short term complications, mostly minor and with a relatively easy learning curve $[11,12]$.

\section{CONFLICT OF INTEREST}

The authors confirm that this article content has no conflict of interest.

\section{ACKNOWLEDGEMENTS}

Declared none.

\section{REFERENCES}

[1] Flynn JM, Schewend RM. Management of paediatric femoral shaft fractures. J Am Acad Ortho Surg 2004; 12(5): 347-59.

[2] Loder RT, O'Donnel PW, Finberg JR. Epidemiology and mechanism of femur fracture in children. J Pediatr Orthop 2006; 26(5): 561-6.

[3] Bopst L, Reinburg O, Lutz N. Femur fracture in pre- school children; experience with flexible intra- medullary nailing in 72 children. J Pediatr Orthop 2007; 27(3): 299-303.

[4] Mazda K, Khairouni A, Pennecot GF, et al. Closed flexible intramedullary nailing of femoral shaft fracture in children. Pediatr Orthop B 1997; 6(3): 198-202.

[5] Flynn JM, Luedtke LM, Ganly TG, et al. Comparison of titanium elastic nails with traction and spica cast to treat femoral fractures in children. J Bone Joint Surg AM 2004; 86: 770-7.

[6] Narayanan UJ, Hyman JE, Wainwright AM, et al. Complications of elastic stable intra- medullary nail fixation of paediatric femoral fractures and how to avoid them. J Pediatr Orthop 2006; 26(5): $567-72$.

[7] Luhmann SJ, Schootman M, Schoenecker PL, et al. Complications of titanium elastic nails for paediatric femoral shaft fractures. J Pediatr Orthop 2003; 23(4): 442-7.

[8] Moroz LA, Launay F, Kocher MS, et al. Titanium elastic nailing of fractures of the femur in children. Predictors of complication and poor outcome. J Bone Joint Surg Br 2006; 88(10): 1361-6.

[9] Ho CA, Skaggs DL, Tang CW, et al. Use of flexible intramedullary nails in paediatric femur fractures. J Pediatr Orthop 2006; 26(4): 497-504.

[10] Houshian S, Gothgen CB, Padersen NW, et al. Femoral shaft fractures in children. Elastic stable intr- medullary nailing in 31 cases. Acta Orthop Scada 2004; 75(3): 249-51.

[11] Hedin H, Bergquist L, Larssen S. A cost analysis of three method of treating femoral shaft fractures in children. J Bone Joint Surg (Am) 2004; 86: 770-7.

[12] John MF, David LS. Femoral shaft fractures. Rockwood and Wilkins' Fractures in children. $7^{\text {th }}$ ed. China: Lippincott Williams and Wilkins 2010; vol. 22: pp. 797-841. 